\title{
8. Scoping a future research agenda
}

This concluding chapter reflects upon and fleshes out a future research agenda. As interpreted here, such an agenda centres around identifying penetrating themes and questions meriting further reflection and study, rather than aiming for a definitive theoretical or empirical framework. The latter risks becoming too fixed, especially in a context of rapid - and sometimes unexpected - change. Hence, the aim is to provide reflection about and building blocks for a programme for future research, through identifying important concepts, lines of analysis and pertinent questions.

As I near the end of the book, it is helpful to recall the main questions posed: How do women's and men's situations compare and what role does social policy play in affecting these and shaping gender patterns? What are the different ways of addressing gender inequality in social policy and with what results? How is the intersection of gender with other inequalities managed, reproduced or changed by social policy? This chapter is divided into two main parts. The first recalls the main findings and highlights insights from the discussion and analysis in the preceding chapters, while the second part focuses attention on configuring a research agenda. An outline set of research questions brings the chapter to a close.

\subsection{WHAT HAS BEEN HAPPENING IN PRACTICE?}

In line with other work, the analysis undertaken underscores the uneven - asymmetrical even - nature of gender change (Pettit and Hook, 2009; England, 2010; Charles, 2011; Cooke, 2011). It is clear that women's lives have altered significantly, and those of men to a lesser degree. In particular, more women are in the labour market and a greater number have access to some income of their own. These kinds of changes are both reflected in and causal to an increase in dual earner households, which is now the dominant household arrangement among couples with children in the EU as a whole (again mainly because of changes made by women). But it is also obvious that speaking of women and men as global categories is inappropriate in light of the significant differences found between and within population sectors. In this regard, the role of family situation (allied with 
the varying effects of age or life course stage) together with the influence of socio-economic and ethnic group differences stand out. And, of course, national variations dissect the global picture also. I was unable to explore each of the variations - mainly due to data shortages but also because of the scale of the task - but the analyses undertaken leave no doubt about disparities in the experiences and opportunities available to different groups of women (and presumably men). It is important also to remind ourselves that, often when we speak about change and improvement, these tend to be read from the template of the lives of highly-educated, ethnic majority women (thereby also running the risk of over-estimating the degree of change).

Asymmetry also applies in another way. The degree or depth of change varies depending on which of the three spheres one has in focus. However, within this broader systemic asymmetry there is one symmetrical pattern: in the 'private sphere' of family life gender-segregated workloads and responsibilities are both widespread and resilient. A gendered division of family labour lives on despite increasing female employment and movements in class, racial and other lines of division (see also Cooke, 2011). There is a germinal insight about change here: that it is not taking the form of across-the-board degendering of social institutions but, rather, occurring through "processes of partial, domain-specific equalization" (Charles, 2011, p. 357). This is reflected in the outcome data reviewed, and specifically the equality scores (as measured by the Gender Equality Index). Of the three main dimensions considered - income, employment and time - any improvements in gender gaps have been driven by increases in women's employment participation and their level of financial resources. But these (rather global) indicators co-exist with little or no improvement over the last decade in gender gaps in overall economic situation, time expenditure (whether time on caring or social activities is the focus) or segregation in and quality of employment. As a result, the overall Gender Equality Index for the EU as a whole improved by just 4.2 percentage points in the ten years between 2005 and 2015, standing at 66.2 out of 100 in 2015 (European Institute for Gender Equality, 2017a).

Another asymmetric element relates to cross-national variation. The evidence confirms continued variation across countries. Again, to take the Gender Equality Index as a convenient summarizing measure, the overall gender gap in 2015 varied from a low of 50 in Greece to a high of 82.6 in Sweden. Relatively strong regional groupings prevail, especially at the extremes. The Nordic and Continental European countries together with Ireland and the UK tend to be at or above the EU average on the global equality indicator whereas the lowest equality scores are concentrated in the Baltic, Central Eastern European and Mediterranean nations. In the 
Baltic and Central European countries especially, high levels of full-time, female and male employment co-exist with significant gender inequality in unpaid work. While the gaps have narrowed in some of the countries (especially Cyprus, Estonia, Italy and Slovenia) over the ten-year period covered by the Index, regional gaps and groupings generally persisted. The fact that the overall gap between the lowest and the highest countries was of a generally similar magnitude in 2015 as it was in 2005 (around 30 percentage points) suggests two things. The first is that countries vary in terms of the scale of gender inequality and that gaps are resilient (given that the ordering and relative placing of countries was generally similar in the two periods). Second, progress overall in reducing variation is rather minimal - a small number of countries made little or no progress over the ten-year period (European Institute for Gender Equality, 2017a, pp. 7-9). These include the Czech Republic, Slovakia and the UK as well as Finland, Hungary and Lithuania. Taken together, these results suggest that we may have to revise our understanding and expectation of change as gradual and progressive, and be open to the possibility of stalling and of structural limits to progress, in the sense of equality thrusts plateauing out.

The variation leads me to suggest that, taking account of the three types of resource considered here and the general policy approach, there are four main routes or patterns to gender equality in the EU at the present time. The first is 'equality mainly through the market' whereby women from all backgrounds have high labour market attachment and this is usually on a full-time basis. High public 'equality' coexists with high private inequality, however, for the division of labour in families is highly unequal with women carrying out most of the labour, as policy generally looks on but does not intervene. The Central Eastern European and Baltic countries, taken as a bloc (and of course there are exceptions), approximate this pattern as does Portugal. These countries are an interesting example of high female labour market participation without divided labour markets in terms of pay and segregation or female participation patterns riven by class (as Pettit and Hook, 2009, suggest is more generally the case). However, inequalities in unpaid work are strong and resilient, and poverty is more widespread than in the Nordic countries. The second route could be described as 'balanced equality in the public and private spheres' - employment patterns of mothers of young children are different to those of other women and men (lower rates, more part-time work) but the gender division of unpaid work is less than it is in the first route. This option is available to highly-educated women in most countries but it is really only in the Nordic countries (albeit with significant national differences) that it is widely available. These countries still provide the best-case scenario for dual income/dual caregiver outcomes (see also Morgan, 2009) and, speaking generally, they show the 
least inequality on the three dimensions considered. Public policies make a strong attempt at equalization across spheres. But it must be emphasized that this regional grouping breaks down once one starts to probe deeply, especially in regard to the relationships between mothers and the labour market. A third route is 'part-time equality' - whereby part-time work provides the pathway into employment for mothers. This is a pattern of limited equality across income, employment and time as a traditional division of labour in the home persists. It may not even be a half-way house towards equality. This pattern conjoins some of the Continental European countries (Austria and Germany, the Netherlands) with Ireland and the UK. Policy is not strongly committed to equality in the division of unpaid work. Fourthly, there is a pattern of 'selective but low-grade equality' for women - highly-educated women are in the labour market often on a fulltime basis whereas women from other educational backgrounds tend to be home-based and large inequalities in unpaid work prevail across the board. Policy more or less fails to problematize gender inequality. Some national exemplars here include Cyprus, Italy and Malta.

This gives rise to two questions: Why has change been so uneven within and across countries? And why has it stalled in some?

My interest inheres in the role of social policy in relation to these and other questions. The legacy (both real life and academic) from the earlier periods highlighted that women have a relationship to and form of dependence upon the welfare state quite different to that of men, with the implications playing out in both micro everyday processes of life organization and more macro-level patterning and structuring. There is little to suggest that this gender-specific relationship pattern has changed significantly. If we think policy should have done better - and there is no reason to exonerate it of that responsibility - the review of policy undertaken showed three main policy-related factors that help explain the outcomes: policy has been selective in terms of which aspects of gender inequality have been targeted; the priority accorded to gender inequality has varied (especially at EU level which was the main locus considered for equality policy); and some of the prevailing social policy orientations and politics now sideline gender inequality as a problem or policy focus. And, in a fourth factor, policy equivocation reflects societal variations and ambivalence. For the European landscape is marked by continuing public support for maternal care of babies and young children in some quarters and systematic differences between the associated moral economy (the norms) and political economy (in terms of where the costs are borne) in others (Shalev, 2009).

In regard to the first, increases in women's involvement in the labour force and higher personal income for women (with the latter secondary to 
the former) have been prominent policy priorities, 'rounded out' by appeals to work-life balance. A rather innovative 'policy playbook' is adopted: paternity and maternity leave, parental leave, ECEC and better support for informal care of adults requiring care (through income and services). A result is a closer relationship now as compared with the past between employment/labour policies and social/family-related policy with the caregiving aspects of family relationships to the fore. 'Fathers' and 'parents' are more present as a focus of policy and more of young children's care is external to the family. However, the extent of the reforms and the gradual and piecemeal pace do not usurp women's role as mothers. The developments have as yet failed to ignite substantial change in gendered patterns of parenting and there has been some correction in those countries (e.g. Sweden) which had moved strongly towards defamilialization.

Secondly, the EU, for long a leader in gender equality reform, does not treat it with the priority it once did, although rhetorically gender equality is still prominent in EU discourse and gender equality programmes continue to exist. The single strongest thrust of the EU orientation over time has been its favouring of an anti-discrimination approach. This was consequential for gender between the 1970s and the 1990s especially, with a number of Directives addressing overt discrimination against women in social security systems and employment. It has also been deployed more recently to address discrimination on other grounds, especially race and disability. Gender mainstreaming - the competing social policy approach to gender inequality at EU level which targets change in the institutions and processes of policy making and seeks to generalize a concern with gender equality across the policy system - was actively pursued for a time from the 1990s but in the last ten years or so has been downgraded. It is important to note that gender mainstreaming yielded large advances in evidence and data, especially in regard to resources enabling cross-national comparisons, and in honing our understanding and assessment of 'progress'. Probably the EU's Gender Equality Index owes some of its origins to gender mainstreaming, for example. Moreover, some of the ideas inherent in gender mainstreaming as an approach to policy have stuck - like a better sharing of domestic tasks and responsibilities and a 'work-life balance' - but, fatally in the views of some, they have been 'coopted' onto agendas centred upon economic and employment growth (Stratigaki, 2004, 2005). Overall, there is evidence of an economic growth rationale for equality acting to displace rationales deriving from equality, social justice and societal betterment. Moreover, it is difficult to find leadership in gender equality policy also among the EU member states at the present time.

Third, the policy rubrics that hold court now - in particular work-life balance and social investment (both outlined in Chapter 7) - do not prob- 
lematize gender equality as a policy priority (although they might view it as a beneficial effect especially if it results in higher female employment rates and - in some countries - higher fertility). These approaches tend to think in gender-neutral categories. The two-earner household is now seen to be the best chance for economic survival/prosperity. It has the twin advantage of effecting greater self-sufficiency on the part of individuals and households, and reducing public expenditure. The new model being promoted in Europe is not the full-time, dual earner arrangement but rather a combination model whereby women (and men to a lesser extent) are enabled to manage and combine care-related and employment activity. Here family considerations are central. On my reading Europe is not moving to a dual earner model in any unilinear way but it is shifting away from the expensive male breadwinner model that requires high subsidies from both the state and employers (in terms of the numbers of people that one wage has to support), regulation of the labour market and compromise if not sacrifice from many women.

That said, in many ways policy reflects public attitudes which still express significant affinity to traditional gender patterns, especially in a context of child-rearing and family life. This is the fourth causal factor. Maria Charles has pointed out that the most resilient gender inequalities are those that are not explicitly hierarchical and appear to reflect naturally distinct preferences of autonomous women and men (Charles, 2011, p. 367). Even when we take account of variation, it seems that Europe as a whole still favours a familialist response to gender equality challenges. This, among other things, complicates the politics involved (Morgan, 2009; Shalev, 2009).

In these times, it is striking how much pay and associated gender inequalities have come to be the dominant narrative in relation to financial inequality, reflecting on the one hand a general trend to downgrade the income support role of the welfare state in favour of the economy, and on the other a tendency to simplify and funnel complex issues into singular rubrics. Furthermore, there has been little movement to change the valuation of traditionally female activities and jobs, a change which feminist work has long identified as essential to gender equality. In the absence of such a shift, men have had little or no incentive to change and the incentive structures for women have pushed them in the direction of either gendered traditional or (for them) non-traditional activities and positions (England, 2010). The creeping thread of reform in social policy in Europe was to induct women into largely unchanged structures rather than a more integrated female and male perspective that would change those structures and/or provide a stronger basis for social justice and collective organizing. Put simply: it is difficult to see contemporary social policy developments 
coming out of a wish for a larger stake for women or even significant redistribution towards women. Note also that the mainstream in which the EU and member countries sought to integrate women has been itself increasingly reshaped by neoliberal policies (especially since the recession of 2008).

The next section of the chapter draws out a research agenda, thinking of this at both a conceptual and policy level. As the discussion proceeds, it will focus on a number of tensions central to the field.

\subsection{A FUTURE RESEARCH AGENDA}

Looking forward, a central plank of engagement has to be the underlying gender system and how it is maintained and changed. This may well mean circling around the same set of issues as in the past but we should not apologize for that. The gender system as conceived of here is constituted by the organizing principles and ideologies involved in the way the welfare state constructs relationships and resource differentials between women and men and governs the terms of family, kinship and reproductive/productive relations. Going forward, four main issues mark out key elements of researching the gender system: the meaning of gender equality and the role of social policy; the relationships and intersections among race, class, and gender (among other lines of differentiation) as axes of inequality; the significance of unpaid work and its relationship to paid work and gender equality; and the interconnections between local, national and global contexts. I will discuss each of these in turn, remaining mindful that they intersect and also involve core tensions that are beyond my capacity to resolve here.

\subsubsection{Gender Equality and the Purpose of the Welfare State}

A matter that needs continuing revisiting is how we should conceive of gender equality and what kind of vision of change is appropriate in a social policy and welfare state context. This, admittedly, is complex and difficult. Plantenga and Remery (2013, p. 36) point out that it is not obvious that women's position is strengthened or improved by virtue of being 'equal' to men in terms of hours of employment, for example. We might extend this point also to the Gender Equality Index and other similar indices that measure progress in terms of sameness and give the nod to equality by also including indicators of 'private life'.

There is no agreement in feminist or other circles regarding equality, although the unacceptability of inequality is widely shared. In both 
academic and policy work, a root question centres around sameness versus difference. For some, the ultimate goal is the elimination of the gender division of labour and of asymmetry between women and men such that both work for pay and participate in family-related care giving in equal measure (Gornick and Meyers, 2008, 2009). This kind of vision is inherent in the idea of the dual earner/dual carer household as an equality ideal which has been elaborated in the work of Nancy Fraser (1994), Diane Sainsbury (1999) and Janet Gornick and Marcia Meyers (2008), among others. An alternative vision - based on a philosophy that draws upon difference rather than sameness - focuses more on choice within a context of continuing gender differences. No particular overall household model is proposed here, not least because one of the theoretical foundations is of diversity in preferences. As articulated by Ann Orloff (2008, p. 4), this supports "political goals that would expand choice, or decisional autonomy, based in interdependence, and inclusive citizenship, emerging from a consideration of diversity in modern societies and from an understanding of gender as constitutive of subjects". There is a strong sense of open individual agency involved. Orloff is especially concerned that we take account of the persistence - and legitimacy - of continuing differences in gender-related attitudes and popular beliefs and people's deep investments in gender (the possibility that women and men do not want to be 'the same') and also the challenges to universalistic approaches and visions posed by difference and diversity, especially in a context of high immigration and population diversity. Another factor is the known significant variation in preferences along socio-economic, ethnic and other lines. Analysis indicates that a sameness understanding of equality tends to accord most with the orientations and lifestyles of highly-educated, ethnic majority women (Shalev, 2009).

These considerations should act as a caution in setting up normative models. And they, too, invite searching questions about the role of social policy. Thinking about choice and difference from a social policy perspective underlines the need for policy intervention and provision (rather than the more obvious obverse). Working in a more global context, Razavi and Staab (2018) remind us that for any policy reform to succeed a supportive infrastructure needs to be in place. Orloff (2008) in the quote above underlines this point with her reference to 'inclusive citizenship'. The idea of not constraining choice is in some ways also one of the key insights from the capabilities approach, although its focus is arguably on enabling choice with its emphasis on social policy's role in affecting means rather than determining ends (Sen, 1992, 1999; Nussbaum, 2000). As explained by Lewis and Giullari (2005, p. 88), the approach makes important distinctions between the resources available to a person (means), what she is and does (functionings), the personal, social and environmental factors that 
affect her ability to transform means into functionings (conversion factors) and the combination of 'beings' and 'doings' that she has the real freedom to achieve (her capability set). Agency is central but so too is the degree of value placed on different aspects of life (and their cognitive and cultural coding). This approach accords social policy quite an important place in either promoting or impeding people's ability to achieve capabilities (Hobson, 2014, p. 12). Kurowska (2018) points out that implicit in the approach is a role for policy in shaping the means available to people but at the same time allowing people to translate them into 'capabilities' and 'functionings'.

For this and other reasons, there are limits to a liberal interpretation of choice, especially if choice and freedom are read as calling for state disinvestment to allow for increasing incursion of the market. Then it means choice for some rather than all. The interpretation and realization of choice need to be carefully thought through, therefore. Indeed, as I said above, we may posit that a necessary condition of choice for all - especially those on low incomes or with fewer resources - is state provision. My sense is that we need to keep asking the question of what constitutes progress in gender equality and to view this exercise as involving problematizing the balance between choice and constraint and the policy packages associated with each for all categories of women and men. We must keep interrogating the mainstream neoliberal policy model (as an approach that targets women as economic actors only) while seeking alternatives to it. In this and other regards, I consider it important to keep the focus on resources and how policy affects resource holding/usage and associated inequalities. The vision that underpins this book - inequality as inhering in the gender division of resources of money, labour and time - seems like a serviceable framework going forward, although there are some blindsides regarding aspects of identity and immaterial welfare.

Thinking more broadly and in a manner inclusive of immaterial as well as material concerns, Sandra Fredman's (2016) conception of substantive equality is helpful to consider. Working in the context of the EU legal system, she develops her framework in the shadow of two challenges: to move from formal equality to substantive equality and to do so in a way that absorbs the challenges of an intersectional perspective. Rather than being based on sameness, it explicitly incorporates differences in power positioning and relationships. Thinking in terms of a legal framework and especially overcoming the limits of an anti-discrimination approach in EU law, she treats equality-oriented measures as having four complementary functions: redress disadvantage (the redistributive dimension); address stigma, prejudice, stereotyping and violence (the recognition dimension); facilitate participation and voice (the participative dimension); and accom- 
modate difference through structural change (the transformative dimension). Power is central to her perspective in which intersecting relationships of power can be analysed according to the extent to which they (i) create socio-economic disadvantage; (ii) are stigmatic, prejudiced, stereotyping or violent; (iii) exclude or marginalize; and (iv) require conformity. This framework gives a sense of the breadth of the field. The different elements vary in the extent of their relevance for social policy - with the first three of most direct pertinence - but in key ways all are relevant and as an overall framework it shows promise in envisioning and interrogating what we might expect of law and policy.

\subsubsection{Insights from Intersectionality}

Intersectionality has to have a more central place in future studies of inequality. One can see why from some of the results of the analyses carried out in this book, albeit that it adopted what might be called a 'light-touch intersectional approach', systematically searching for differences in the situation of different groups of women - especially along family status, age and social class lines - and conceiving of people's lives, policies and associated inequalities as cutting across spheres and particular patterns of resource holding and usage. Proceeding in this way helped to reveal not just the inter-connections between different types of inequalities but gender as itself cut through by other axes of division. The results confirm some key lessons from existing work that should be taken seriously, especially the following points made by Choo and Ferree (2010) in their state-of-the-art review: the importance of recognizing that multiple stratification processes exist; that they are not independent of one another; and that it is vital not to leave uncritiqued the differences of the groups under study from an assumed norm.

That said, there are real challenges in employing an intersectionality approach. This is not just because of methodological or data issues but is also a function of conceptual challenges in holding questions of race, class, gender, sexuality, and other social categories and related processes in the frame at once (and doing so in a theoretically informed way). At the risk of being prosaic, intersectionality is a complex framework and way of thinking. There is also the fact that intersectionality has become rather elastic in its meaning and neoliberal in its application by policy (as we have seen in relation to the EU's engagement with the concept which frames it in a diversity management register). All of this raises questions about the approach's place in feminist studies and whether its origins in black feminism and Third World liberation movements are being erased and sanitized as it has moved to become a more mainstream approach 
(Salem, 2018). I am convinced that we must continue to develop and integrate an intersectionality perspective in our work and that this must serve to focus on both marginalized groups and marginalizing processes. I am also convinced that gender can serve as one over-arching frame for it defines and organizes key commonalities that transcend particular lines of difference. So we can go in search of the underpinning gender system but treat it as a multi-dimensional entity (Htun and Weldon, 2018) and be open to the possibility that the underlying inequality or stratification is not solely gender-based.

The situation of men is especially pertinent in this context. Research in the social policy field has yet to incorporate a perspective on men as a heterogeneous social group in their own right and in relation to the lives of women (with some notable exceptions in the work of Hearn (2010), Hobson and Morgan (2002) and Dermott and Miller (2015)). In a lot of scholarship, men are either the residuals (but also the norm against which we (and society) construe and judge progress) or, in a more active vein, working and engaged fathers. Bringing men in is important in its own right, given the prevalence and consequences of hegemonic masculinity and the fact that gendered patterns of male behaviour are complicated by other social and cultural factors.

Some suggestions about how to take forward intersectional thinking in social policy studies can be gleaned from existing work. Ciccia and Sainsbury (2018) make the point that intersections have been most studied as outcomes (as here), whereas what is needed are "comparative approaches to disentangle the contextual and intersectional effects of inequalities in shaping the division of welfare" (p. 104). The underlying call here (on my reading) is to examine how intersections lead to and are based on diverse but connected marginalizations, understood in terms of access to power and grounded in material relations and resources, and how these play out in different settings within and across nations. Another line of thought comes from Siim and Borchorst (2017) who suggest that a vision of political intersectionality concerned with the interplay of 'redistribution policies' and 'recognition struggles' could be a useful strategy for revisioning gender and welfare regimes. Although I have not studied it specifically here, recognition merits a central place in gender and social policy studies. In regard to researching policy, Bacchi (2017) is in line with key elements of an intersectional perspective when she suggests moving away from categories or categorical distinctions in policy analysis altogether (because they hide the processes, practices and politics involved in the formation of these categories) and, rather, think in terms of processes generated by policy. This picks up on intersectionality's strong sense of needing to move beyond status markers. It means two things: that we can rely only 
to a limited extent on global, uni-dimensional gender indicators and that we need to try and divine the processes (the 'ing/ization') underlying them. This shifts the focus from how policies affect women and men to asking how they help constitute them. In this view, the questions we should pose to policy are 'complex how questions', such as: How is policy active or complicit in creating/perpetuating differences and inequalities between women and men in ways that are also racializing, and/or classing, and/or heteronorming, and so forth?

\subsubsection{Familial Considerations, Care and Social Reproduction}

The findings of this book underline the resource-related and other inequalities associated with care giving, for women especially. The direct costs involve the expenditure of time, energy and other material and immaterial resources in activities and commitments that have lesser public value in comparison to paid work. The indirect costs extend over the longer term and include such possible outcomes as insecurity in employment, career and income, reduced or no access to social protection benefits, delimited participation opportunities in education and training, all compounded in increased poverty risk, especially in old age.

As is clear from the foregoing - especially Chapter 2 - care has become a very important concept in the analysis of the material covered in this book. As an overarching concept it has developed to pick up on and organize some of the key lines of family-related policy development (and also health-related policy). While it does not encompass them and they pre-date care as a concept to some extent, the intelligence of the concept has allowed lines of analysis like maternalism or familialization/ defamilialization to flourish. Moreover, as a tool for policy analysis (and it is much more than that for some of its theorizations extend to existential philosophy and societal reorganization), care picks up on core aspects of the way that the welfare state is being reformed, keeping the spotlight on family considerations and their gendered framing (e.g. whether this is through increasing use of gender-neutral terminology like 'parent', 'carer' or something else).

As well as the above, there are a number of interesting and fruitful forms of enquiry in relation to care that are interesting to consider from a future-oriented view.

One prominent line of analysis is the care economy. This concept is being developed especially by feminist economists. Nancy Folbre is a leading scholar here (see Folbre, 2018) as is Sue Himmelweit (2014). In policy circles the Economic Commission for Latin America and the Caribbean is a noteworthy actor (ECLAC, 2004; Mahon, 2018b), shifting the focus from 
women's labour market participation to inequalities in the paid and unpaid division of labour and focusing on trends like the growth of paid domestic labour and of transnational care migration and 'care chains' which reach across the world. De Hanau et al. (2016) ${ }^{1}$ conceptualize the care economy to include activities in education, care, health services and social care. Concerned especially about the concealed and under-resourced nature of much of care provision and increasing marketization, such theorizing seeks to make the hidden visible and to do so in a way that is sensitive to larger trends and global changes. Nancy Folbre (2009, p. 111 and passim) encourages us to think more broadly also; she emphasizes a framing of care that encompasses the organization and financial support for all care services (as against just child care). In underlining that "the social provision of a generous, equitable, sustainable, and efficient supply of care is a prerequisite of genuine gender equality" (p. 112), she makes three specific proposals for research and policy:

- Look beyond work-family policies such as paid parental leave and publicly provided child care to develop policies of economic support for all forms of family, friend, and neighbour care;

- Look beyond family care to the organization, cost and quality of paid care services;

- Develop better accounting systems for both economic growth and welfare state spending.

Folbre's call underlines the broad convening power of the concept of care. But - placed in a European context especially - it goes somewhat against the grain of recent scholarship in the field which has focused on the specificity of care (policies) for children as against those for long-term care for adults (e.g. Ranci and Pavolini, 2015; Dobrotić and Blum, 2019; Le Bihan et al., 2019). There is certainly a tension here, especially as both are becoming more diverse, and arguably more complex as policy fields (especially elderly care). The utility of a singular framing needs to be questioned by research going forward in my view. In the next section I will raise the question of the utility of care vis-à-vis social reproduction to pick up on the complex of factors driving gender inequality.

For now I wish to highlight that there are dangers in positioning care in economic and market terms. One risks, for example, thinking of care in terms of economic principles and economic rationalization. There are, then, reasons to keep a critical distance from conceptualizing care in

1 Available at http://www.ituc-csi.org/IMG/pdf/care_economy_en.pdf. 
economic terms. But whether that means that we should reject concepts like the care economy is open to question. It allows us to pose challenging questions like the degree to which the positioning of care in economic and market terms effects a commodification of care; the processes and consequences of promoting economic principles and economic rationalization in care as an activity that is fundamentally relationally based; and the contradictions of economization and marketization for those of us who hold that care workers/providers should not be treated as a source of cheap labour (Williams, 2018a, 2018b). And, of course, marketization is part of the political economy of care. We know something about the politics of ECEC through social investment-oriented analyses (e.g. Morgan, 2009) but long-term care as a social policy field is much less often seen through the lens of social investment and is also less analysed from a political economy perspective (in social policy anyway). In some respects, this is because it is only recently - with greater longevity and a less readily available supply of familial care - that it has become prominent and contested as a policy issue. While we do know something about the vested interests involved (corporations for example, or other providers - see Farris and Marchetti, 2017) and outsourcing (Estévez-Abe and Hobson, 2015; Morel, 2015), the alignment of the interests of commercial actors with those of other actors remains largely underexplored.

\subsubsection{Crisis, Contemporary Global Capitalism and the State}

Given the contemporary discourse about economic recovery, it may be tempting to consign the recession of 2008 to history. This would be ill-advised for its effects on our politics, economies, welfare states and philosophies around gender reach deeply and widely. The recession was generally taken as an opportunity in Europe - and on the part of the EU - to promote austerity as well as continuing to shift responsibilities and resources from the state to individuals, families, communities and markets. There is a risk also of seeing the recession and austerity as one-off events. I suggest that we should phrase our questions in the present and future tenses, mindful, of course, of the need for an account that is historically sensitive.

Making the link to prevailing economic models propels a question about which concepts and theories we should use to uncover and explain gender inequality. I want to frame this issue through a discussion of the strengths and merits of care as an analytical device as regards those of social reproduction. One can definitely claim for care a sensitivity to family and a capacity to encompass different modalities and dimensions of care (at different levels). However, Mignon Duffy's work (2005; see also Duffy and 
Armenia, 2019) makes the case that much of the field remains dominated by studies of family care giving. This, it is claimed, has lent the scholarship a strong orientation towards care as nurturance (and hence, relationality and interdependence), thereby marginalizing another theoretical strand of (earlier) feminist work - domestic labour and social reproduction. The latter, while overlapping somewhat with the relationality field of work on care, is different in two key respects (Duffy, 2005). First, theoretically, the social reproduction perspective situates care-centred work in the economy and exigencies around the reproduction of the labour force. Secondly, expanding the field to include both nurturant and non-nurturant versions of care captures a much broader universe of workers (such as those involved in food preparation, house cleaning and laundry). Duffy's application of this categorization to employment data in the US Census of 2000 confirms this, as well as uncovering a racial divide whereby women of colour as compared with white women are over-represented among nurturant care occupations (although they remain over-represented compared to white women in non-nurturance jobs as well). This leads Duffy (2005, pp. 78-9) to conclude that a theoretical focus on care as nurturance appears to privilege the experiences of white women over the more varied experiences of women of colour and to exclude large numbers of very low-wage workers. ${ }^{2}$

Vershuur (2013) also picks up the criticism about care's focus on nurturing. Whilst recognizing the strengths and contribution of the scholarship on care, she is critical of it for focusing most attention on the nature of the labour involved as against the broader political economy and the articulation between the productive and reproductive spheres and how this changes over time (when care comes to be part of paid labour or a care economy, for example). While this may overstate care's focus on the relations and engagement involved and, indeed, underplay their significance, there is a serious point about the explanatory capacity and reach of both concepts. In earlier feminist work which used social reproduction as the leading framework of analysis, domestic labour was treated as embedded in a set of economic relations and linked to exploitation rather than devaluation. It could be argued to have stronger economic depth than care, being especially interested in the extent of the subsidy provided by social reproduction to public welfare and the economy in general (Kofman and Raghuram, 2018). In a prescient development of the concept, Rai et al. (2014) articulate the idea of 'depletion through social reproduction'

2 It is important to note that her definition of nurturant jobs includes such occupations as teachers, social workers, clergy, nursing, and a whole range of medical and dental practitioners. 
to draw out the costs of non-recognition and lack of support for social reproduction. Depletion is for these authors a tipping point when resource outflows exceed resource inflows over a threshold of sustainability, making it harmful for those engaged in this work (whether individuals, households or communities). They identify three ways in which depletion can be reversed. The first is through mitigation (when individuals or other units might decide to pay for help, although they note that this can increase depletion further down the chain for those who cannot afford to pay). The second strategy is replenishment - whereby states or private bodies contribute to resource inflows (through services, financial help and so forth). Transformation is the third mode of reversal. Here they reference both a restructuring in the gender division of labour and recognizing and valuing social reproduction. There are clearly similarities with care here but work on it tends to go in a different direction.

I consider it important that we recognize the strengths and weaknesses of each concept and be conscious and judicious in our use of them. In the aim of adding context to the previous discussion, it is important to point out that studies using care have furnished a detailed and rich analysis of welfare and health policies. This, more a European than a US literature, has helped to open up and systematize the analysis of services to meet (care) needs. The service provision aspects of the welfare state have been especially elaborated (see e.g. Anttonen and Sipilä, 1996), providing an important corrective to the heavily transfer-related focus of welfare state studies. The concept of care has also, as I have said above, brought in familial considerations to a degree that work on social reproduction has not (yet).

Whichever concept we use it needs to be able to link developments across borders to bring in global capitalism and international development, especially in terms of the articulation between the national and global economies in relation to care-related labour and service organization. This will have to decentre the nation state as the unit of analysis to focus on global migrations and international patterns of resource flows, especially in a context of climate and other change. One of the foremost challenges is to identify and explain how and why the depletion of resources in the Global North is leading to depletion in the Global South and how social class, race and other axes of inequality are involved. Understanding the use of migrant (mainly female) workers to fill mounting gaps and deficits in care provision in the high-income countries as native-born women increasingly (re-)enter the workforce is an important link to powerful underlying processes (Budig and Misra, 2011; Hochschild, 2012). De los Reyes (2016, p. 39) sees some of the promise of an intersectional approach here: ". . . an intersectional perspective of the imbrications of class, race, sexuality and 
gender can be a point of departure for understanding the different ways that current capitalist accumulation models are recreating bio-political assumptions of the human through processes of commodification and the emergence of new modalities of governance".

We have already seen that scholarship is making such interconnections, broadening the scope of policy analysis courtesy of its interest in how policies on race, ethnicity and migration interact and are patterned in such a way as to render care giving (and often care receiving) a continued site and conduit of inequality within and across borders. Recognizing this starts to fill a gap in our understanding of how care is associated with complex inequality that both defines and transcends the national space. Williams (2018a, 2018b) has suggested a three-level framework: at a micro level the everyday experience of care and care work; at meso level the institutional infrastructure; and at macro level developments in global capitalism. Michel and Peng (2017) use what they call a multi-scalar approach (which also embraces micro, meso and macro interconnections) to examine three domains: care provisioning; the supply of and demand for care work; and the shaping and framing of care. In important respects, these scholars are merging insights from work on care and social reproduction.

One important way of ensuring that our perspectives are sufficiently sensitive to the exploitation caused by our lives in the global North is to enquire about the conditions under which they are sustainable and in particular whether they can be sustained only on the basis of an asymmetrical global economy (Hassim, 2009, p. 96). In other words, can the arrangements and privileges around care and welfare be universalized? Hassim sets out the conditions of global egalitarianism: we need to expand our model beyond the formal economy; be vigilant in regard to the socialization of care jobs; and acknowledge more overtly the global context of care and the need for global redistribution which guarantees access to the basic means of survival as well as the power to determine the content of international regulatory frameworks $\left(2009\right.$, p. 105). ${ }^{3}$ All of these questions become more urgent in a context of climate change.

\subsection{KEY RESEARCH QUESTIONS}

Overall, it is clear that examining the relationship between gender and social policy is not just a vibrant field of research but essential to understanding core aspects of contemporary lives. Regarding the relation-

3 See also Razavi and Staab (2018). 


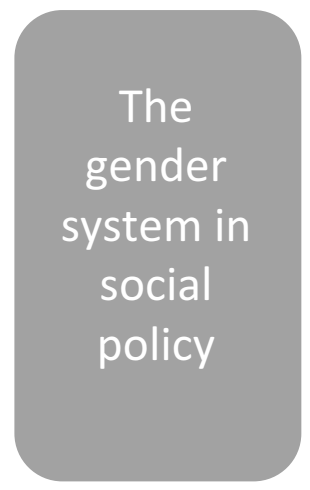

- What gender-related assumptions and divisions does social policy take forward?

-What are the incentives/disincentives in policy from a gender perspective?

-Where is the relevant innovation (if any) in the social policy system, what are the origins and likely consequences?

- Are gender inequalities being reinscribed in new ways as policies develop and reform?

- Has equality plateaued out and are there structural limits to equality?

- How should we think of men and male interests and how do we find a way of deepening our conceptualization and critique of men's relationship to social policy (in a way that recognizes differences among men)?

- To what extent is the social policy system effecting gender inequality through other inequalities, and vice versa?

-What explains the different routes to gender equality found across countries and what are the divergences and convergences?

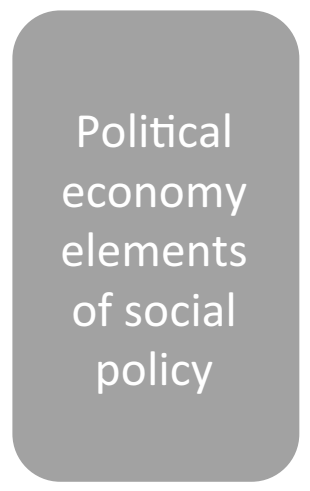

-Who benefits from social policy provision?

- Who bears the costs of existing arrangements?

- Thinking in a more global context: where are the costs borne and what is the sub-national, national, regional and global patterning and relative privileging/disprivileging?

- Which are the actors involved in the reorganization of care and social reproduction, especially in its commodification and marketization? How is this connected to wider economic processes?

-What is the scale and nature of the role of the family (or relations of kinship) in resource exchange and support?

-What and where are the risks of care-related depletion?

- Which capabilities are essential for women and men and is

choice only possible for well-off women and men?

-What are the racial interests and underpinnings in social policy and its reform?

- Has the approach that targets women only as economic actors been exhausted as a solution to gender inequality and what should replace it?

- How is the recession of 2008 and associated policy consensus transforming the welfare state and its place in economy and society?

Figure 8.1 Important questions for a future research agenda

ship between social policy and gender, the central concerns that have dominated scholarship - women's relationship to the welfare state project, the relationship between care, paid work, and welfare, the links between care, social reproduction and gender inequality - are as important as ever (Orloff, 2009). But they need to be considered and expanded through perspectives that take account of intersectional inequalities, a critical reconceptualization of unpaid work and care, and the interlinking of 
local, national, regional and global developments in a framework that problematizes resource flows and endangered sustainability. This book has attempted to illustrate, rather than exhaust, the possibilities. There are many ways in which the research reported here invites critical test and extension. I end with some potentially penetrating questions, loosely organized under two broad headings: the gender system and political economy (which of course are integrally related). These questions are envisaged to be applied at a range of levels. 